Written asthma action plans

\section{Written asthma action plans}

\section{R Partridge}

\section{More widespread use of written asthma action plans should be encouraged}

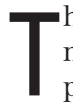
he first British guidelines for the management of asthma in adults published in 1990 clearly recommended self-management of asthma. The exact statement read: "As far as possible, patients should be trained to manage their own treatment rather than be required to consult their doctor before making changes". ${ }^{\text {I Similar advice }}$ has been repeated in subsequent revisions of the UK guidelines ${ }^{2-4}$ and in the NHLBI global strategy for asthma management and prevention. $^{5}$

The evidence base for these recommendations is strong, and 36 trials comparing self-management education with usual care were reviewed for the Cochrane Library. ${ }^{6}$ This review suggested that self-management education could be associated with a reduction in hospital admissions of up to $40 \%$, a reduction in emergency room visits of $20 \%$, and similarly impressive reductions in unscheduled visits to the doctor, night time symptoms, and days off work or school. The authors concluded that training programmes that enabled people to adjust their medication using a written asthma action plan appeared to be more effective than other forms of self-management. In this issue of Thorax Gibson and Powell ${ }^{7}$ report the results of a further review to determine what is important about personalised written asthma action plans. They conclude that such plans are best when using 2-4 action points which involve increasing the dose of inhaled steroid and initiation of oral steroid therapy for exacerbations. Plans using peak flow should be based on personal best peak expiratory flow.

The evidence, however, is thatdespite a 13 year history of such advice being recommended-implementation of these recommendations is poor. Indeed, in one study of a stratified group of 785 adults and children with asthma, only $3 \%$ of respondents had been given a written self-management action plan setting out what they should do if their asthma deteriorated. ${ }^{8}$ This study was performed in a group of people with asthma of all severities. In another population of 378 individuals surveyed 1 week after an acute episode of asthma necessitating unscheduled access to health care, $28 \%$ of patients reported having a written self-management plan. ${ }^{9}$ Nevertheless, three quarters of people with clear evidence of out of control asthma had not been equipped with the tools necessary to control their own condition-tools which have been recommended for over 13 years.

The question must therefore be asked as to why-in the presence of such a plethora of data in favour of selfmanagement education and personalised asthma action plans-are so few patients actually receiving this advice? Possible reasons include:

- Patient factors (very stable well controlled disease; patient does not wish to take control of his/her condition ${ }^{10}$ ).

- Health professional factors, for example:

- lack of awareness of the recommendations;

- erroneous belief that all asthma attacks are acute:

- lack of confidence in patients selfmanaging their own condition;

- dislike of self-management because (in some healthcare systems) it leads to loss of income;

- lack of physician confidence in teaching patients self-management skills;

- perceived lack of time.

Failure to implement recommendations contained within guidelines is, of course, not confined to failure to offer patients with asthma written personalised action plans. However, there may be specific barriers to implementation of such educational advice because of lack of specific training and knowledge regarding what should be given in the way of self-management advice and personal asthma action plans. Nonavailability of partially preprinted material on to which advice may be written may also lead to patients not receiving such plans.

Numerous studies have shown that, at least among adults, most asthma exacerbations, while often severe, are not acute. One study showed that 56\% of adults admitted to hospital with severe asthma had experienced night time waking for at least 5 nights before admission. ${ }^{11}$ In another national census of those attending UK accident and emergency departments with asthma, one fifth of adults had been kept awake by their asthma for more than 3 nights before attendance. ${ }^{12}$ A study in Canada found that one fifth of patients with asthma admitted to hospital and one fifth of those requiring intensive care had had symptoms for at least 21 days before admission. ${ }^{13}$ These studies suggest that, for most patients with troublesome asthma, plenty of time was available for either the patient or the doctor to alter treatment to avoid deterioration to the point where the patient needed to be admitted to hospital.

\section{"There can be no further excuse for delaying widespread implementa- tion of . . . written personal asthma action plans"}

In some healthcare systems the concept of devolving care to the patient may have negative financial implications for health professionals. This might lead to them being reluctant to implement recommendations regarding the issuing of personal asthma action plans. It would be a pity if the beneficial results from 36 good clinical trials were to be negated by such financial considerations. Perhaps such colleagues could be convinced of the advantages of a partnership approach to medical care by pointing out that, in another study, over $30 \%$ of patients who scored their physicians as being "non-participatory" changed physicians over the subsequent year, whereas those who scored their physicians as being "participatory" were half as likely to report that they would change their physician in the following 12 months. ${ }^{14}$

Time is needed to teach patients how to recognise signs of deteriorating asthma and to teach self-management skills, but Clark and colleagues have shown that such training, when offered in the context of an interactive educational seminar, can have a lasting effect on physician behaviour and better outcomes, and consultation times are not necessarily extended. ${ }^{15}$ In some healthcare systems such tasks are helpfully shared with nursing colleagues.

In their paper in this issue of Thorax, Gibson and Powell ${ }^{7}$ emphasise that action plans which involve both increasing inhaled steroid dosage and taking steroid tablets are the most effective, yet some may perceive a controversy with regard to increasing the dose of inhaled steroids. The British asthma guidelines ${ }^{4}$ 
state that the value of doubling the dose of inhaled steroids is unproven. However, this statement must be seen within the context of most of the published studies of self-management education which have included a description of the action plans used, recommending a doubling or trebling of the dosage of inhaled steroids. This paradox can be explained either by understanding that advice to double the inhaled steroids is only effective if given within the wider context of selfmanagement education, or by an appreciation that it is the concept of varying dosage of medications that is important rather than the actual magnitude of change. It may be that the advice in zone 2 of a personalised asthma action plan also works by reminding the noncompliant patient to take his or her inhaled steroid. A further explanation is that doubling alone may not be sufficient. An Italian study suggested that the most efficacious interventions were probably those which involved reducing the dose of inhaled steroid when well controlled and then quadrupling it at the first sign of loss of control of asthma. ${ }^{16}$ The need for us to teach patients how to both increase and decrease their dose of inhaled steroids is exemplified by recent work which showed that, in a group of adults with asthma, the active practice of stepping down treatment was associated with a mean reduction in daily inhaled steroid usage of $348 \mu \mathrm{g}$ beclomethasone equivalent per day, with equally good outcomes to those who had stayed on a fixed dose. ${ }^{17}$

Patients with many long term conditions fail to comply with their therapeutic regimen. Many understandably express negative views regarding their "dependence" on regular medication, and many patients stop, start, or vary the dose of their medication. Selfmanagement education and the issuing of personalised written action plans permit us to hand control of their condition to patients in such a way that they vary their dose of medication in a scientific manner, rather than according to whim. Patients dislike the uncertainty associated with a variable condition such as asthma, and they dislike dependency upon health professionals.
Teaching patients how to vary their dose of asthma medication according to their symptoms and according to the severity of their condition returns control to them and has been shown to be associated with enhanced compliance. ${ }^{18}$ Health service usage by those with asthma is reduced by such actions and it is likely that, overall, there may be a reduced usage of medication and financial benefits. ${ }^{19}$ There can be no further excuse for delaying widespread implementation of the issuing of written personal asthma action plans. Gibson and Powell have given us a clear steer as to the important constituents of such plans. Further research is still needed into which subgroups of those with asthma benefit most, and why, for some such as the repeatedly hospitalised, ${ }^{20}$ such benefit is less.

How we encourage self-management education and the issuing of personalised asthma action plans by health professionals is similarly unclear. ${ }^{21}$ Part of the failure may have been our failure to teach better what is involved or may reflect poor availability of materials. Part may reflect lack of motivation of healthcare professionals or lack of time. It will be of interest to see how much the financial incentive of the asthma $3+$ visit plan in primary care improves implementation in Australia. ${ }^{22}$

Thorax 2004;59:87-88.

doi: $10.1136 /$ thx.2003.016451

Correspondence to: Professor M R Partridge Imperial College of Science, Technology and Medicine, Charing Cross Hospital Campus, London W6 8RP, UK:

m.partridge@imperial.ac.uk

\section{REFERENCES}

1 British Thoracic Society, Research Unit of the Royal College of Physicians of London, Kings' Fund Centre, National Asthma Campaign. Guidelines for management of asthma in adults: 1 - Chronic persistent asthma. BMJ 1990;301:651-3.

2 British Thoracic Society, British Paediatric Association, Research Unit of the Royal College of Physicians of London, et al. Guidelines on the management of asthma. Thorax 1993:48(Suppl 2):S1-24.

3 British Thoracic Society, National Asthma Campaign, Royal College of Physicians of London in association with the General Practitioners in Asthma Group, et al. The British guidelines on asthma management: 1995 review and position statement. Thorax 1997:52(Suppl 1):S1-22.
4 British Thoracic Society and Scottish Intercollegiate Guidelines Network. British guideline on the management of asthma. Thorax 2003:58(Suppl I):i1-94.

5 National Institutes of Health, National Heart, Lung and Blood Institute (NHLBI). Global strategy for asthma management and prevention. NIH publication no 023659. Update from NHLBI of the WHO workshop report. Bethesda, MD: NHLBI, 1995; (revised 2002)

6 Gibson PG, Powell H, Coughlan J, et al. Selfmanagement education and regular practitioner review for adults with asthma (Cochrane Review). In: The Cochrane Library. Issue 1. Oxford: Update In: The Cochrane

7 Gibson PG, Powell H. Written action plans for asthma: an evidence based review of the key components. Thorax 2004:59:94-9.

8 Price D, Wolfe S. Delivery of asthma care: patients' use of and views on healthcare services as determined from a nation-wide interview survey. Asthma J 2000:5:141-4.

9 Pinnock $H$, Johnson A, Young $P$, et al. Acute asthma attacks - the patients' perspective. Asthma J 2000;5:130-2.

10 Jones A, Pill R, Adams S. Qualitative study of use of health professionals and patients on guided self management plans for asthma. BMJ 2000;321:1507-10.

11 Blainey D, Lomas D, Beale A, et al. The cost of acute asthma - how much is preventable? Health Trends 1990/1;22:151-3.

12 Partridge MR, Latouche D, Trako E, et al. A national census of those attending UK accident and emergency departments with asthma. J Accid Emerg Med 1997:14:16-20.

13 Turner MO, Noertioj K, Vedal S, et al. Risk factors for near fatal asthma. A case controlled trial study in hospitalised patients with asthma. Am J Respir Crit Care Med 1998:157:1804-9.

14 Kaplan SH, Greenfield S, Gandek BMS, et al. Characteristics of physicians with participatory decision making styles. Ann Intern Med 1996; 124:497-504

15 Clark NM, Gong M, Schork MA. Long-term effects of asthma education for physicians on patient satisfaction and use of health services. Eur Respir J 2000;16:15-21.

16 Foresi A, Morrelli MC, Catena E. Low dose budesonide with the addition of an increased dose during exacerbations is effective in long term asthma control. On behalf of the Italian Study Group. Chest 2000;117:440-6.

17 Hawkins G, McMahon AD, Twaddle S, et al Stepping down inhaled corticosteroids in asthma: randomised control trial. BMJ 2003:326:1115.

18 Gallefoss F, Bakke PS. How does patient education and self management among asthmatics and patients with chronic obstructive pulmonary disease affect medication? Am J Respir Crit Care Med 1999;160:2000-5.

19 Gallefoss F, Bakke PS. Cost effectiveness of self management in asthmatics: a one year follow up randomised, controlled trial. Eur Respir J 2001;17:206-13

20 Osman LM, Callder C, Godden DJ, et al. A randomised trial for self management planning for adult patients admitted to hospital with acute asthma. Thorax 2002;57:869-74.

21 Clarke NM, Partridge MR. Strengthening asthma education to enhance disease control. Chest 2002;121:1661-9.

22 Fardy HJ. The 3+ plan for asthma management. Aust Fam Physician 1999:28:95. 
Staging of COPD

\section{COPD in the ECRHS}

\section{J Vestbo}

\section{More work is needed on the concept of staging of COPD}

A $s$ a junior doctor I once worked in a hospital where the leading consultant in medicine refused to accept the diagnosis of asthma in patients older than 40 years. To him, airflow obstruction was "asthma" in the young and "chronic bronchitis" in the elderly. While it soon became apparent that asthma does occur after the age of 40 , the likelihood of significant airflow limitation occurring in young adults who have never had asthma has always seemed small to me. In this issue of Thorax De Marco et al describe the prevalence of chronic obstructive pulmonary disease (COPD) in young adults taking part in the European Community Respiratory Health Survey (ECRHS). ${ }^{1}$ They found COPD to be a considerable issue; in total, $3.6 \%$ had COPD stage I+ according to the NHLBI/WHO Global Initiative for Chronic Obstructive Lung Disease (GOLD) ${ }^{2}$ and $11.8 \%$ had chronic respiratory symptoms without airflow limitation-that is, COPD GOLD stage 0 .

The study raises several questions relating to methodology, findings, and interpretation. Diagnosis and staging of COPD was done according to the GOLD guidelines ${ }^{2}$ using an $\mathrm{FEV}_{1} / \mathrm{FVC}$ ratio of 0.7 and $\mathrm{FEV}_{1}$ cut off points of $80 \%, 50 \%$, and $30 \%$. In subjects aged $20-44$ years a ratio of 0.7 will not overestimate airflow obstruction-more likely it will underestimate it. The major challenge seems to be exclusion of asthma and the approach of De Marco et al can, to some extent, be questioned. In contrast to GOLD recommendations, prebronchodilator $\mathrm{FEV}_{1}$ was used for staging but this seems acceptable in the epidemiological setting where administration of bronchodilators is often not feasible. Patients with self-reported asthma without cough/phlegm were excluded while those with both self-reported asthma and chronic symptoms were considered to have COPD with coexisting asthma. The latter seems intuitively correct in a 44 year old heavy smoker with a smoking history of 30 pack years, but is it true in the 20 year old never smoker with self-reported asthma? Unfortunately, no valid answers exist; GOLD has not attempted to separate stage 0 COPD from symptomatic asthma, and only for subjects with irreversible airflow limitation does GOLD acknowledge the problem: "Poorly reversible airflow limitation associated with bronchiectasis, cystic fibrosis, tuberculosis, or asthma is not included except insofar as these conditions overlap with $\mathrm{COPD}^{\prime \prime} .{ }^{2}$ In the Copenhagen City Heart Study cohort $^{3}$ $54 \%$ of women and $63 \%$ of men with self-reported asthma had chronic productive cough; this will presumably remain an issue for debate for some time.

COPD stage 0 denoting subjects "at risk" was introduced by GOLD, but the concept cannot be regarded as evidence based and remains controversial. ${ }^{45}$ It is, nevertheless, intriguing that the prevalence of chronic symptoms in 20-44 year old subjects is more than $10 \%$ on average and as high as $24 \%$ in Spain. Risk factors did not differ substantially between stages 0 and $\mathrm{I}+$, and a recent Italian study has shown that stages 0 and I differ little in health status. ${ }^{6}$ Still, we do need prospective studies of stage 0 including various outcomes. We also have to make clear the reason for applying staging to COPD. Undoubtedly, staging facilitates communication and comparison of study results. It is, however, less clear that it reflects biological changes over time. The concept of cancer staging-where, by definition, patients progress through the stages-may not be valid in COPD. While it is unlikely for anyone to have stage III or IV without passing through earlier stages, COPD stage I can undoubtedly develop without the patient ever having been in stage $0{ }^{4}$ Years of looking at the "Fletcher diagram ${ }^{\prime \prime 7}$ have anchored the impression of rapid decline so firmly in our minds that we may tend to forget that, through impaired growth of lung function in childhood and early adolescence, any superimposed airflow obstruction at a later age could very well start the patient off in COPD stage II. ${ }^{8}$ For this and other reasons, more work on the concept of staging of COPD is clearly needed.

COPD is a burden in the elderly, but it is not a disease of the elderly alone. The notion of COPD in young adults was confirmed by the "confronting COPD" study, ${ }^{9}$ but whereas that study used doctor's diagnosis and presence of symptoms, the ECRHS study has verified the diagnosis with spirometric testing in random population samples, enabling us to quantify the problem. Unfortunately, the study by De Marco et al does not tell us the prevalence of doctor diagnosed COPD in their cohort. COPD is often undiagnosed ${ }^{10}$ and, based on data from the IBERPOC study, this is even more so in younger patients ${ }^{11}$ and in women more than in men. ${ }^{11}{ }^{12}$ In this respect, the ECRHS study showed COPD to be more prevalent in men than in women. When biological explanations are applied to these findings, caution is probably warranted. Better information is available in this area from longitudinal studies $^{13}$ and, in addition, detailed information on smoking such as age of starting and inhalation is essential for adjusting properly for sex differences in smoking habits when addressing susceptibility. ${ }^{14}$

With the study by De Marco et al, however, COPD epidemiologists now have to join asthma epidemiologists in praising the ECRHS. One important question remains: How should these findings change our perception of COPD? They probably should not! The strengths of the paper lie in the finding that COPD is a widespread problem in young adults and the implications of the quantification. To limit case finding and/or screening for COPD to middle aged or elderly subjects would be missing a window of opportunity based on these findings.

Thorax 2004;59:89-90.

doi: $10.1136 /$ thx.2003.018598

Correspondence to: Professor J Vestbo, North West Lung Centre, Wythenshawe Hospital Southmoor Road, Manchester M23 9LT, UK. jvestbo@man.ac.uk

\section{REFERENCES}

1 De Marco R, Accordini S, Cerveri I, et al. An international survey of chronic obstructive pulmonary disease in young adults according to GOLD stages. Thorax 2004:59:120-5.

2 Pauwels R, Buist A, Calverley P, et al. Global strategy for the diagnosis, management and prevention of chronic obstructive pulmonary disease. $\mathrm{NHLBI} / \mathrm{WHO}$ global initiative for chronic obstructive lung disease (GOLD) workshop summary. Am J Respir Crit Care Med 2001;163:1256-76.

3 Lange P, Parner J, Vestbo J, et al. A 15-year follow-up of ventilatory function in adults with asthma. N Engl J Med 1998;339:1194-200.

4 Vestbo J, Lange P. Can GOLD Stage 0 provide information of prognostic value in chronic obstructive pulmonary disease? Am J Respir Crit Care Med 2002;166:329-32.

5 Cerveri I, Corsico A, Zoia MC. GOLD stage 0. Am J Respir Crit Care Med 2003;167:936.

6 Antonelli-Incalczi R, Imperiale C, Bellia V, et al. Do GOLD stages of COPD severity really correspond to differences in health status? Eur Respir J 2003;22:444-9. 


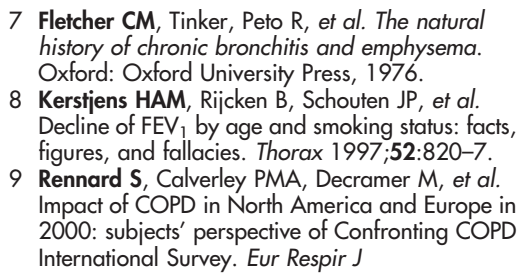

7 Fletcher CM, Tinker, Peto R, et al. The natural history of chronic bronchitis and emphysema. Oxford: Oxford University Press, 1976.

8 Kerstiens HAM, Rijcken B, Schouten JP, et al. Decline of $F E V_{1}$ by age and smoking status: facts, figures, and fallacies. Thorax 1997;52:820-7.

9 Rennard S, Calverley PMA, Decramer M, et al. Impact of COPD in North America and Europe in 2000: subjects' perspective of Confronting COPD International Survey. Eur Respir J 2002;20:799-805.
10 Coultas DB, Mapel D, Gagnon R, et al. The heath impact of undiagnosed airflow obstruction in a national sample of United States adults. Am J Respir Crit Care Med $2001 ; 164: 372-7$

11 Pena VS, Miravitlles M, Gabriel R, et al. Geographic variations in prevalence and underdiagnosis of COPD. Results of the IBERPOC multicentre epidemiological study. Chest 2000;118:981-9.

\section{New insights into oxygen sensing at a cellular level}

\section{S R Walmsley, K K K Sheares, A Sobolewski, N W Morrell, E R Chilvers}

\section{The oxygen sensing pathway offers a new set of therapeutic targets for conditions ranging from inflammatory lung disease to pulmonary hypertension}

$\mathrm{T}$ he ability of cells to detect and respond to a fall in oxygen tension is of fundamental importance for maintaining oxidative metabolism and tissue homeostasis. One of the challenges facing scientists working in this area has been that any proposed mechanism for oxygen sensing has to accommodate the very different tolerances of certain tissues to hypoxia and the extreme variation in the cellular responses observed. Hence, while skeletal muscle cells can recover function after 30 minutes of anoxia, the brain suffers irreparable damage after only 46 minutes of ischaemia. ${ }^{1}$ Moreover, while carotid body cells respond to changes in oxygen tension that barely register in non-chemosensory tissues (and do so within seconds), ${ }^{2}$ upregulation of erythropoietin synthesis in the interstitial peritubular cells is transcriptionally regulated and requires far more protracted periods of hypoxaemia. $^{3}$ Despite such variances in oxygen sensitivity and response time, all cells appear capable of responding to hypoxia and the essential components of a universal oxygen sensing mechanism have at last begun to emerge. Moreover, from studies conducted in stroke and heart disease, it is apparent that therapeutic targeting of this novel pathway is set to transform our approach to pathology previously deemed intractable.

\section{RESEARCH STUDIES}

Initial clues into how cells respond to low oxygen came from studies undertaken in the early 1990s examining the hypoxic response element (HRE) of the erythropoietin (Epo) gene. This led to the identification of a transcriptional activator called hypoxia inducible factor (HIF). ${ }^{4}$ HIF is a heterodimer composed of HIF-1 $\beta$ (or aryl hydrocarbon receptor nuclear translocator, ARNT), which is constitutively expressed, and HIF- $1 \alpha$ whose expression and transcriptional activity are tightly regulated by the ambient oxygen concentration. ${ }^{5}$ Once formed, this protein complex migrates to the cell nucleus and, together with the co-activator $\mathrm{CBP} / \mathrm{p} 300$, binds to the HREs present on the promoter region of genes involved in regulating metabolic supply and demand. ${ }^{6}$ Examples of HIF regulated genes include those involved in regulating vascular tone (for example, iNOS and adrenomedullin), angiogenesis (for example, vascular endothelial growth factor, VEGF), cell metabolism (for example, lactate dehydrogenase $\mathrm{A}$, the glucose transporter GLUT-1), and haemoglobin biosynthesis (for example, erythropoietin). ${ }^{7}$ These findings, together with the ubiquitous nature of HIF and the demonstration that HIF deficient animals show major defects in many core physiological responses to oxygen, have resulted in HIF being regarded as one of the master regulators of the cellular response to hypoxia. $^{8}$

The next step in this quest was to define the mechanism responsible for hypoxic induction of HIF-l $\alpha$. Through a combined structural and genetic approach, it has now been possible to show that HIF-l $\alpha$ activity is regulated by enzymatic hydroxylation at
12 Chapman KR, Tashkin DP, Pye DJ. Gender bias in the diagnosis of COPD. Chest 2001;119:1691-5

13 Watson L, Boezen HM, Postma DS. Differences between males and females in the natural history of COPD. Eur Respir Monogr 2003;25:50-73.

14 Prescott E, Osler M, Vestbo J. Importance of detailed adjustment for smoking when comparing morbidity and mortality in men and women in a Danish population study. Eur J Publ Health 1998;8:166-9.

specific prolyl and asparaginyl residues by a novel 2-oxoglutarate dependent class of dioxygenases. ${ }^{9}$ Critically, these enzymes have been shown to display an absolute requirement for oxygen in addition to iron $\left(\mathrm{Fe}^{2+}\right)$ and ascorbate. These oxygen sensitive enzymes inhibit HIF activity in a complementary manner since the prolyl hydroxylase domain containing enzymes (PHDs) result in an interaction between HIF- $1 \alpha$ and the von HippelLindau protein which targets HIF- $1 \alpha$ for proteosomal destruction, ${ }^{10}$ and factor inhibiting HIF (FIH) causes asparaginyl hydroxylation and blocks HIF association with $\mathrm{CBP} / \mathrm{p} 300 .{ }^{11}{ }^{12}$ Hence, under normoxic conditions, HIF- $1 \alpha$ levels remain low and this prevents the transcription of genes containing HRE promoters (fig 1).

\section{CLINICAL APPLICATIONS}

How does this inform our understanding of the pathophysiology of lung disease and can it provide the basis of novel therapies? Mice homozygous for a null mutation in the HIF- $1 \alpha^{13}$ or HIF- $1 \beta$ genes $^{14}$ die at mid gestation with vascular defects primarily involving the embryonic and extraembryonic circulation, respectively. In contrast, HIF- $1 \alpha^{+/-}$ mice develop normally and are indistinguishable from wild type littermates. However, when exposed to $10 \%$ oxygen for up to 6 weeks, the HIF- $1 \alpha^{+/-}$ mice demonstrate reduced susceptibility to pulmonary hypertension, polycythemia, and right ventricular hypertrophy relative to their wild type littermates. ${ }^{15}$ Morphometric analysis showed that the chronically hypoxic HIF- $1 \alpha^{+/-}$mice have fewer completely muscularised pulmonary arterioles and the degree of muscularisation in such vessels is reduced compared with HIF- $1 \propto$ wild type mice. Thus, HIF-l appears to play a major role in mediating pulmonary vascular remodelling in chronic hypoxia, and therapeutic manoeuvres that inhibit HIF-1 activity in the lung may slow the progression

Abbreviations: ARNT, aryl hydrocarbon receptor nuclear translocator; $\mathrm{FIH}$, factor inhibiting HIF; HIF, hypoxia inducible factor;
HRE, hypoxic response element; PHD, prolyl hydroxylase domain containing enzyme 


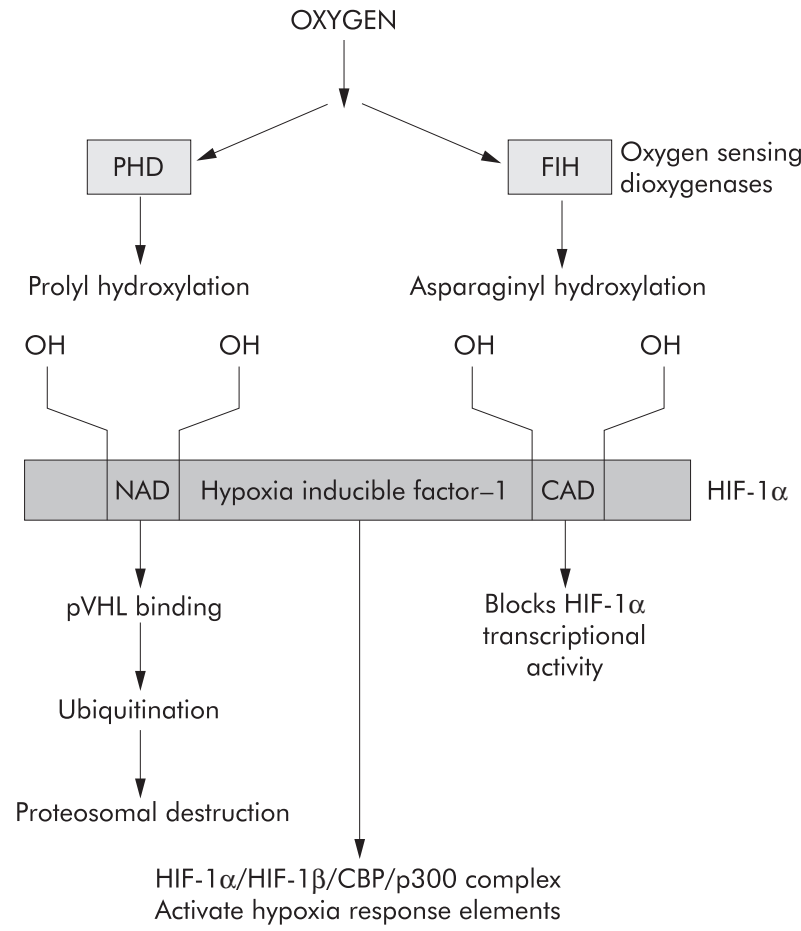

Figure 1 Oxygen dependent inhibition of HIF- $1 \alpha$. Under normoxic conditions the oxygen requiring PHD and FIH dioxygenases lead to prolyl and asparaginyl hydroxylation of HIF-1 $\alpha$ which results in proteosomal destruction and inhibition of transcriptional activity. PHD, prolyl hydroxylase domain containing enzyme; FIH, factor inhibiting HIF; NAD, amine activation domain; $C A D$, carboxyl activation domain; pVHL, von Hippel-Lindau protein.

of hypoxia induced pulmonary hypertension.

Likewise, in many human cancers including primary lung tumours, increased levels of HIF- $1 \alpha$ expression are associated with resistance to tissue hypoxia and enhanced tumour angiogenesis. ${ }^{16}$ This abnormality correlates with a reduced sensitivity to radiation and chemotherapy and disease progression. ${ }^{17}$ Moreover, in vitro work has shown that depleting tumour cells of HIF- 1 renders them more radioresponsive and thus provides an opportunity to enhance the therapeutic potential of conventional treatment. ${ }^{18}$ In addition, by targeting bioreductive pro-drugs to hypoxic tumour sites, the potential for normal tissue damage can be reduced.

One of the real surprises in this area of research, however, has been the recent demonstration of the importance of oxygen sensing pathways in the function of inflammatory cells. Hence, in contrast to the effects of hypoxia observed in many other cell types, oxygen deprivation causes a profound but reversible delay in the rate of constitutive apoptosis in human neutrophils. ${ }^{19}$ Moreover, removing the capacity of neutrophils to respond to hypoxia using a myeloid targeted HIF-l $\alpha$ knockout results in a substantial fall in the glycolytic capacity of these cells and, as a consequence, a profound impairment of myeloid cell adhesion migration and bacterial killing. ${ }^{20}$ As persistent accumulation of primed and activated neutrophils is a cardinal feature of a number of lung diseases, these data predict that inhibition of the HIF-l $\alpha$ pathway may promote the resolution of granulocyte inflammation.

One final example of the importance of this pathway relates to the potential to prevent ischaemia-reperfusion injury in the transplanted lung. Hence, in the heart, ischaemic pre-conditioning, which reduces dramatically the degree of myocardial damage observed following subsequent coronary artery occlusion, has been shown to relate to HIF dependent upregulation of erythropoietin. ${ }^{21}$ Indeed, this protein has the capacity to prevent myocardial cell apoptosis, and erythropoietin infusion is effective in reducing infarct size and improving outcome in stroke. ${ }^{22}$ Application of these principles to lung protection is bound to follow.

Despite such striking advances in our knowledge of how cells sense oxygen, much remains to be defined. In particular, it is likely that a quite separate pathway underlies the ability of acute hypoxia to induce membrane depolarisation and L-type calcium channel activity in excitable cells. These events trigger the acute contractile response of pulmonary artery resistance vessels to hypoxia and the firing of carotid body glomus cells. The current contenders in this area are the mitochondrial $\mathrm{NAD}(\mathrm{P}) \mathrm{H}$ oxidases, which are postulated to produce a diffusible redox mediator in response to hypoxia.

\section{CONCLUSIONS}

These studies show that, while cells display widely differing tolerances and responses to hypoxia, oxygen sensing by dioxygenases and their consequent effects on HIF dependent transcriptional events appear to be a property that is shared by most, if not all, cells. This pathway now offers a new set of therapeutic targets for an array of lung diseases ranging from inflammatory lung disease through to pulmonary hypertension.

\section{ACKNOWLEDGEMENTS}

The work in the authors' laboratories is supported by the Wellcome Trust, British Heart Foundation, National Asthma Campaign, MRC, and British Lung Foundation. SRW holds an MRC Clinical Research Training Fellowship and KKS holds a BHF Clinical Fellowship.

Thorax 2004;59:90-92.

doi: 10.1136/thorax.2003.017020

\section{Authors' affiliations}

S R Walmsley, K K K Sheares, A Sobolewski, N W Morrell, E R Chilvers, Respiratory Medicine Division, Department of Medicine, University of Cambridge School of Clinical Medicine, Addenbrooke's and Papworth Hospitals, Cambridge, UK

Correspondence to: Professor E Chilvers, Respiratory Medicine Division, Department of Medicine, University of Cambridge School of Clinical Medicine, Box 157, Level 5 Addenbrooke's Hospital, Hills Road, Cambridge CB2 2QQ, UK; erc24@cam.ac.uk

\section{REFERENCES}

1 Siesjo BK. Cell damage in the brain: a speculative synthesis. J Cereb Blood Flow Metab $1981 ; 1: 155-85$

2 Lahiri S, Rozanov C, Roy A, et al. Regulation of oxygen sensing in peripheral arterial chemoreceptors. Int J Biochem Cell Biol 2001;33:755-74.

3 Goldberg MA, Dunning SP, Bunn HF. Regulation of the erythropoietin gene: evidence that the oxygen sensor is a heme protein. Science 1988;242:1412-5.

4 Semenza GL, Wang GL. A nuclear factor induced by hypoxia via de novo protein synthesis binds to the human erythropoietin gene. Mol Cell Biol 1992; 12:5447-54.

5 Wang GL, Jiang B-H, Rue EA, et al. Hypoxiainducible factor 1 is a basic-helix-loop-helix-PAS heterodimer regulated by cellular $\mathrm{O}_{2}$ tension. Proc Natl Acad Sci USA 1992;92:5510-4.

6 Wenger RH, Gassmann M. Oxygen(es) and the hypoxia-inducible factor-1. Biol Chem 1997;378:609-16.

7 Semenza GL. HIF-1: mediator of physiological and pathophysiological responses to hypoxia. J Appl Physiol 2000;88:1474-80.

8 Wenger RH. Cellular adaption to hypoxia: $\mathrm{O}_{2}$ sensing protein hydroxilases, hypoxia-inducible 
transcription factors, and $\mathrm{O}_{2}$-regulated gene expression. FASEB J 2002; 16:1151-62.

9 Epstein ACR, Gleadle JM, McNeill LA, et al. C. elegans EGL-9 and mammalian homologs define a family of dioxygenases that regulate HIF by prolyl hydroxylation. Cell 2001;107:43-54.

10 Jaakkola P, Mole DR, Tian Y-M, et al. Targeting of HIF- $\alpha$ to the von Huppel-Lindau ubiquitylation complex by $\mathrm{O}_{2}$-regulated prolyl hydroxylation. Science $2001 ; 292: 468-72$.

11 Lando D, Peet DJ, Whelan DA, et al. Asparagine hydroxylation of the HIF transactivation domain a hypoxic switch. Science 2002;295:858-61.

12 Mahon PC, Hirota K, Semenza GL. FIH-1: a novel protein that interacts with HIF-1 alpha and VHL to mediate repression of HIF-1 transcriptional activity. Genes Dev 2001;15:2675-86.

13 Ryan HE, Lo J, Johnson RS. HIF-1 alpha is required for solid tumor formation and embryonic vascularization. EMBO J 1998;17:3005-15.
14 Maltepe E, Schmidt JV, Baunoch D, et al. Abnormal angiogenesis and responses to glucose and oxygen deprivation in mice lacking the protein ARNT. Nature 1997;386:403-7.

15 Yu AY, Shimoda LA, lyer NV, et al. Impaired physiological responses to chronic hypoxia in mice partially deficient for hypoxiainducible factor 1-alpha. J Clin Invest inducible factor 1-alp

16 Maxwell PH, Dachs GU, Gleadle JM, et al. Hypoxia-inducible factor-1 modulates gene expression in solid tumors and influences both angiogenesis and tumor growth. Proc Natl Acad Sci USA 1997:94:8104-9.

17 Aebersold DM, Burri P, Beer KT, et al. Expression of hypoxia-inducible factor-1 lalpha: a novel predictive and prognostic parameter in radiotherapy of oropharyngeal cancer. Cancer Res 2001;61:2911-6.

\section{$\alpha_{1}$-Antitrypsin deficiency}

\section{J K Stoller}

\section{A new series focusing on this important and under-recognised illness}

A lpha $_{1}$-antitrypsin (AAT) deficiency is a common but underrecognised clinical entity. ${ }^{1-3}$ The editors of Thorax have therefore commissioned a series of papers by internationally recognised experts on the key clinical and investigative concepts in this important disease, which will offer the reader an up to date summary of AAT deficiency. Topics to be addressed include:

- the epidemiology of AAT deficiency;

- genetic aspects of AAT deficiency: phenotypes and genetic modifiers of emphysema;

- clinical manifestations and natural history of AAT deficiency;

- molecular pathophysiology of AAT deficiency;

- pathogenesis of lung disease in AAT deficiency;

- intravenous augmentation therapy for AAT deficiency: current understanding;

- new and emerging therapies for AAT deficiency; and

- CT imaging in AAT deficiency.

Why this attention to AAT deficiency now? As mentioned above, despite the fact that it affects up to one in 1600 newborn infants, ${ }^{2}$ AAT deficiency is both under-recognised and "underunderstood". ${ }^{3}$ As evidence of this under-recognition, in a survey of 300 $\mathrm{PI}{ }^{*} \mathrm{ZZ}$ individuals the mean interval between the appearance of the first attributable symptom (almost invariably dyspnoea due to fixed airflow obstruction) and the diagnosis of AAT deficiency in a group of mean age 49 years was 7.2 years. ${ }^{3}$ Furthermore, $44 \%$ of the respondents reported seeing at least three physicians before the diagnosis of AAT deficiency was made. In the United States, of the expected $80000-100000$ with severe AAT deficiency $\left(\mathrm{PI}{ }^{\star} \mathrm{ZZ}\right)$, fewer than $10 \%$ have been clinically recognised. ${ }^{4}$

Since establishing the diagnosis is both easy (a simple blood test for a serum level and, if low, a phenotype to secure the diagnosis) and relatively inexpensive (less than \$US200 for a serum level or a phenotype in most commercial laboratories and widespread availability of free testing services), there are ample opportunities to increase recognition of the condition by enhancing clinicians' diagnostic suspicion of AAT deficiency.

What clinical features should clinicians look for? As discussed in this series $^{5}$ and in a recently published evidence-based standards document on the diagnosis and management of individuals with AAT deficiency, ${ }^{6}$ AAT deficiency should be suspected in patients with fixed airflow obstruction (especially in the absence of cigarette smoking or predisposing occupational exposures), in individuals whose family history suggests emphysema and/or liver disease, and in those with suggestive clinical characteristics-for example, basilar hyperlucency on the chest
18 Unruh A, Ressel A, Mohamed HG, et al. The hypoxia-inducible factor-1 alpha is a negative factor for tumour therapy. Oncogene 2003;22:3213-20.

19 Mecklenburgh KI, Walmsley SR, Cowburn AS, et al. Involvement of a ferroprotein sensor in hypoxia-mediated inhibition of neutrophil apoptosis. Blood 2002;100:3008-11.

20 Cramer T, Yamanishi Y, Clausen BE, et al. HIF- $1 \alpha$ is essential for myeloid cell-mediated inflammation. Cell 2003;112:645-57.

21 Cai Z, Manalo DJ, Wei G, et al. Hearts from rodents exposed to intermittent hypoxia or erythropoietin are protected against ischaemia-reperfusion injury. Circulation 2003; 108:79-85.

22 Ehreneich $\mathbf{H}$, Hasselblatt $M$, Dembowski C, et al. Erythropoietin therapy for acute stroke is both safe and beneficial. Mol Med 2002;8:495-505.

radiograph, bronchiectasis that is otherwise unexplained, panniculitis, or cirrhosis for which a known aetiology such as viral hepatitis, haemochromatosis, or Wilson's disease is not evident.

Why make the diagnosis of AAT deficiency? As with all diseases, the impetus to diagnose is the desire to ameliorate the adverse effects of the illness, to prolong life, to improve the quality of life of affected individuals and, in the case of a genetic disease like AAT deficiency, to counsel at risk family members in order to encourage health attentive behaviour and treatment that will lessen the likelihood of disease and/ or forestall its progression. Indeed, it is important to establish the diagnosis of AAT deficiency as a number of interventions are available that can produce a beneficial outcome. ${ }^{7-11}$ For example, population screening studies suggest that individuals identified as having $\mathrm{PI}^{\star} \mathrm{ZZ}$ AAT deficiency at birth are less likely to start smoking or to continue smoking than age matched adolescent peers. ${ }^{12}{ }^{13}$ Furthermore, although no definitive randomised clinical trial has established the clinical efficacy of augmentation therapy ${ }^{14}$-currently the intravenous infusion of purified pooled human plasma $\alpha_{1}$-antitrypsin-the results of many observational studies strongly suggest its clinical efficacy. ${ }^{9} 1015$ Indeed, a recent standards document from the Canadian Thoracic Society ${ }^{16}$ and the aformentioned evidence-based standards document which is supported and endorsed by the European Respiratory Society, the American Thoracic Society, the American College of Chest Physicians, the American Respiratory Care Foundation, and the Alpha-1 Foundation ${ }^{6}$ both conclude that augmentation therapy has clinical efficacy. ${ }^{17}$ As reviewed in this series of articles, new and emerging therapies offer the prospect of even more effective treatments that can be made available to individuals known to have severe AAT deficiency. ${ }^{18}$

It is hoped that this comprehensive review will enhance the recognition of 


\section{EDITORIAL}

individuals with AAT deficiency by clinicians and foster optimal medical management.

Thorax 2004;59:92-93.

doi: 10.1136/thorax.2003.017517

Correspondence to: J K Stoller, Division of Medicine, Cleveland Clinic Lerner College of Medicine, Section of Respiratory Therapy,

Department of Pulmonary/Critical Care Medicine, Cleveland Clinic Foundation, 9500 Euclid Av, Cleveland OH 44195, USA; stollej@ccf.org

\section{REFERENCES}

1 O'Brien ML, Buist NRM, Murphy WH. Neonatal screening for alpha 1-antitrypsin deficiency. J Pediatr 1978;92:1006-10.

2 Sveger T. Liver disease in alpha 1-antitrypsin deficiency detected by screening of 200,000 infants. N Engl J Med 1976;294:1316-21.

3 Stoller JK, Smith P, Yang P, et al. Physical and social impact of alpha 1-antitrypsin deficiency: results of a survey. Cleve Clin J Med 1994:61:461-7.

4 Silverman EK, Miletich JP, Pierce JA, et al. Alpha 1-antitrypsin deficiency: high prevalence in the $\mathrm{S}$
Louis area determined by direct population screening. Am Rev Respir Dis 1989;140:961-6.

5 Needham M, Stockley RA. Clinical manifestations and natural history of alpha 1-antitrypsin deficiency. Thorax 2004;59 (in press).

6 American Thoracic Society/European Respiratory Society. Standards for the diagnosis and management of patients with alpha 1antitrypsin deficiency. Am J Respir Crit Care Med 2003; 168:818-900

7 Wewers MD, Casolaro MA, Sellers SE, et al Replacement therapy for alpha 1-antitrypsin deficiency associated with emphysema. N Engl J Med 1987;316:1055-62.

8 Stoller JK, Rouhani F, Brantly M, et al. Biochemical efficacy and safety of a new pooled human plasma alpha(1)-antitrypsin, Respitin. Chest 2002; 122:66-74.

9 Seersholm N, Wencker M, Banik N, et al. Does alphal-antitrypsin augmentation therapy slow the annual decline in $\mathrm{FEV}_{1}$ in patients with severe hereditary alphal-antitrypsin deficiency? Wissenschaffliche Arbeitsgemeinschaft zur Therapie von Lungenerkrankungen (WATL) alphal-AT study group. Eur Respir J 1997; 10:2260-3.

10 The Alpha-1-Antitrypsin Deficiency Registry Study Group. Survival and FEV1 decline in individuals with severe deficiency of alphalantitrypsin. Am J Respir Crit Care Med 1998; 158:49-59.
11 Wencker M Fuhrmann B, Banik N, et al Longitudinal follow-up of patients with alpha(1)protease inhibitor deficiency before and during therapy with IV alpha(1)-protease inhibitor. Chest 2001;1 19:737-44.

12 Sveger T, Piitulainen E, Arborelius M Jr. Lung function in adolescents with alpha 1 -antitrypsin deficiency. Acta Paediatr 1994;83:1170-3.

13 Wall M, Moe E, Eisenberg J, et al. Long-term follow-up of a cohort of children with alpha 1-antitrypsin deficiency. J Pediatr 1990; 116:248-51.

14 Dirksen A, Dijkman JH, Madsen F, et al. A randomized clinical trial of alpha(1)-antitrypsin augmentation therapy. Am J Respir Crit Care Med 1999;160(5 P+1): 1468-72.

15 Minai OA, Stoller JK. Therapy for alpha 1-antitrypsin deficiency: pharmacology and clinical recommendations. BioDrugs 2000;13:135-47

16 Abboud RT, Ford GT, Chapman KR, and the Standards Committee of the Canadian Thoracic

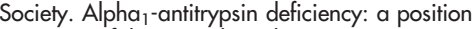
statement of the Canadian Thoracic Society. Can Respir J $2001 ; 8: 81-8$.

17 Stoller JK. Augmentation therapy for severe alpha 1-antitrypsin deficiency: is the jury still out on a trial? Thorax 1998;53:1007-9.

18 Sandhaus RA. New and emerging therapies for AAT deficiency. Thorax 2004 (in press). 